\title{
Microbial processes of arsenic methylation, demethylation and volatilization in paddy soils
}

FANG-Jie ZHAO ${ }^{1}$, CHUAN CHEN $^{1}, \mathrm{Ke} \mathrm{HuANG}^{1}$

1 College of Resources and Environmental Sciences, Nanjing Agricultural University, Nanjing, China.Fangjie.Zhao@njau.edu.cn

Arsenic methylation, demethylation and volatilization are important components of the As biogeochemical cycle. These processes are accelerated under the anaerobic conditions in paddy soils. Microbial groups mediating these processes in paddy soils are poorly understood. Using metabolic inhibition, quantification of functional gene transcripts, microbial enrichment cultures and 13Clabeling experiments, we show that sulfatereducing bacteria (SRB) and methanogenic archaea are involved in As methylation and demethylation, respectively, controlling the dynamics of methylated As species in paddy soils. We present a model of As biogeochemical cycle in paddy soils, linking the dynamics of changing soil redox potential with arsenite mobilization, arsenite methylation and subsequent demethylation driven by different microbial groups. We further present evidence for two different pathways of volatilization of methylated As species, driven by different microbial groups in paddy soils 